\title{
Chemotherapy Safe Handling through Educating Nurses: A Pre-Experimental Study
}

\author{
Rakhi Mishra, MScN ${ }^{1 *}$, Bhawana, $M S c N^{2}$, and Ajay Kushwaha, $\mathrm{MScN}^{3}$ \\ ${ }^{1}$ Assistant Professor, College of Nursing, All India Institute of Medical Sciences, Rishikesh, Uttarakhand, \\ India \\ ${ }^{2}$ Nursing Tutor, College of Nursing, All India Institute of Medical Sciences, Rishikesh, Uttarakhand, India \\ ${ }^{3} \mathrm{MSc}$ Nursing, Nightingale Institute of Nursing, Noida, India
}

*Corresponding author: Rakhi Mishra, MScN, Assistant Professor, College of Nursing, All India Institute of Medical Sciences, Rishikesh, Uttarakhand, 249203 India, Tel: 9513470564

\begin{abstract}
Introduction: Chemotherapy is a proven prodigy for the treatment of carcinoma but it can possess certain deleterious effects on the healthcare professionals while on constant exposure. Being frontline workers, nursing officers continuously come in contact with these chemotherapeutic agents. Hence, it is of paramount importance that nurses working in oncology unit have adequate knowledge and skill regarding safe handling of chemotherapeutic drugs.
\end{abstract}

Materials and methods: Pre-experimental one group pretest post-test design was adopted to accomplish the objectives. Non-probability convenience sampling technique was used to select 30 nurses working in the oncology care unit. The data was collected using structured knowledge questionnaire and observational practice checklist. The obtained data were analysed and interpreted using descriptive and inferential statistics.

Results: The mean pre-test knowledge and practice score was $17.5( \pm 2.28)$ and $9.13( \pm 1.52)$ respectively. However, the post-test knowledge and practice score were $27.03( \pm$ $1.73)$ and 13.8 ( \pm 1.09$)$ that reveals improvement knowledge and practice after structured teaching program. The calculated t test value was 26.78 and 28.91 for knowledge and practice which is highly significant at 0.05 level.

Conclusion: The study findings concluded that the Structured Teaching Program has improved the knowledge and practice of nurses regarding safe handling of chemotherapeutic drugs and it is highly recommended that the nurses need periodic and consistent update knowledge supported by policies to enforce guideline implementation.

\section{Keywords}

Chemotherapy drugs, Effectiveness, Knowledge, Program, Practice

\section{Introduction}

Cancer is a disease characterized by uncontrolled and unregulated growth of cells in a living organism impartially affecting people from all races, age and/or ethnicities. It is one amongst second largest killer diseases after cardiac disorders. About 18 million cases were reported in 2018, out of which, 9.5 millions were male and 8.5 million were female [1]. Approximately, 1 in 6 death occurs due to cancer which further adds 9.6 million cases to mortality rates. It is projected that almost two-third of all cancer cases may occur in the developing countries with $70 \%$ current death rates [2-4]. To take the edge of this life threating illness, there are multiple treatments available ranging from radiation therapy, surgery, immunotherapy, monoclonal antibody therapy to chemotherapy depending upon the location, grade and stage of the tumour.However, systemic treatment modality in these times is becoming major choice of treatment and it is prudent that chemotherapy has brought revolution to the treatment of cancer and kept this fatal disease under tight rein [5].

With increased advancement of technology comes more safeguards as it may prove deleterious for those who are in constant contact with these agents [6]. 
Cytotoxic drugs kill tumour cells by interfering with cell division; because of this ability, they are potentially harmful to normal cells as well. Hazards involved due to the widespread use of cytotoxic drug had led to concerns among hospital personnel involved in their use. A recent literature suggests that $17 \%$ of nurses working in chemotherapy department have been exposed to these drugs on their skin or eyes [7]. Furthermore, accidental exposure of chemotherapeutic drug(s) can possibly impede reproductive system by two-folds, retard nervous system and increase the likelihood of developing blood cancers $[6,7]$. A study done in Brazil reported that 75.75\% nursing officers exposed to chemotherapeutic agents had audiometric notch, $56.25 \%$ had complaints of dizziness and all of them showed alteration in caloric test (100\%) [8]. A macro scale RCT performed on about 56,000 registered nurses of Canada stated that they were put in jeopardy on account of their health due to increased risk of developing cancer in rectum and breast post occupational exposure to cytostatic agents [9].

The harmful effects caused by these mutagens and teratogens due to recurrent exposure are unerring and hence, frontline health workers coming repeatedly in contact with chemotherapeutic agents are most vulnerable. Despite the risk, many healthcare personnel fail to follow the recommended guidelines when handling these drugs. An Indian cross-sectional study revealed that almost $40 \%$ of the staff working in a tertiary care institution had insufficient knowledge regarding cytotoxic drug handling [10]. A current study by Devi S, et al. reported that majority (55\%) of nursing officers had poor level of knowledge and nearly half $(51.7 \%)$ had average practice skills [11]. Overall, it is reported that cytotoxic drug preparation and handling was consistently identified as a greatest risk to health.

Nursing personnel's play a significant role during chemotherapy preparation and administration [11]. This group of health care professionals should possess high levels of knowledge and positive behaviors towards the safe management of chemotherapy. Therefore, the level of knowledge and practice techniques of safe handling of chemotherapeutic drugs becomes a major safety concern.

Hence, the present study was conducted with the aim to assess the effectiveness of Structured Teaching Program on level of knowledge and practice regarding safe handling of chemotherapeutic drugs among nurses working in oncology unit of selected hospital of Delhi, NCR.

\section{Material and Methods}

The present quantitative study adopted pre-experimental one group pre-test post-test design and was conducted from $15^{\text {th }}$ December to $15^{\text {th }}$ January 2017 at Jaypee Hospital, Greater Noida which is a tertiary care multi-specialty facility with currently 525 functional beds. Present study setting was chosen because of easy availability of samples, familiarity with the hospital, geographical proximity, expected cooperation with the participants and administrative approval.

\section{Sample size and sampling criteria}

Non-probability purposive sampling technique was used to select study participants. Thirty (30) nurses who were working in the oncology unit, available during data collection and who was willing to participate were included in the study. Nurses who did not gave consent and had already attended formal teaching program on chemotherapy drug handling were excluded from the study.

The sample size was calculated through Rao soft (2004), with a 5\% margin of error and 95\% confidence level from a population size of 40 . The calculated sample size was 37 . However, data was collected from 30 subjects as they met inclusion and exclusion criteria.

\section{Ethical consideration}

Prior ethical approval was obtained from Institutional Ethics Committee (IEC) vide letter no 1128/NIN/PRI/ FV/2016. Details about study objectives and outcomes were explained to study participants and written informed consent was obtained form all the study participants. Anonymity and confidentiality of data was also ensured.

\section{Instruments}

Data was collected from participants under three sections. Section I: Socio-demographic characteristics including age, gender, educational qualification, years of experience, Attended any certification course on oncology nursing? Section II: Structured knowledge questionnaire on safe handling of chemotherapeutic drugs - It consist of thirty (30) multiple choice questions to assess knowledge on safe handling of chemotherapeutic drugs and the knowledge score was arbitrarily classified as Good (21-30), Average (11-20) and Poor (1-10). Section III: Observational practice checklist regarding safe handling of chemotherapeutic drugs - It consists of 16-items to assess practice on safe handling of chemotherapeutic drug and the practice score will be arbitrarily classified as Very Good (13-16), Average (9-12), Poor (5-8) and Very Poor (1-4) (Annexure).

Experts from the field of medical-surgical nursing (5), Oncologist (02) were involved in content validity of structured teaching Program and Data collection Tool. There was $100 \%$ agreement noted for all the items. Reliability of Structured knowledge questionnaire was calculated with Spearman- Brown formula $(r=0.85)$ and reliability of observational practice checklist was calculated using inter-rate formula $(r=0.80)$.

Knowledge and Practice of Nurses working in oncology unit was assessed using structured knowledge que- 
stionnaire and observational practice checklist on Day1. On the same day, a 45 minutes Structured Teaching Program on safe handling of chemotherapeutic drugs was given using PowerPoint presentation. The topics covered were: Definition, Types of chemotherapy, Receiving, Transporting, Preparation and Administration of cytotoxic drugs, Use of PPE and Handling of cytotoxic waste. The method of teaching was Lecture cum discussion. Post-test was conducted on Day- 8 by administering same set of structured knowledge questionnaire and observational practice checklist.

The obtained data was analysed using SPSS version 20. Mean and paired sample' $t$ ' test was calculated at 0.05 level of significance. The calculated $\boldsymbol{t}$ value more than the table value at 0.05 level was considered stati- stically significant. Fisher exact test was used to find association of knowledge and practice score with selected demographic variable at 0.05 level of significance. A $\boldsymbol{P}$ value less than 0.05 was considered statistically significant.

\section{Results}

Table 1 depicts that Majority (53\%) of respondents were above 25 years of age, Predominantly females (67\%). Nearly two-third (77\%) were GNM with more than one year of working experience in the specialty (67\%). Post-Interventional knowledge score was significantly associated with certification course in oncology nursing at 0.05 level of significance.

Table 2 shows that the Majority (100\%) participants

Table 1: Demographic characteristics of participants and their association with knowledge and practice scores $(\mathrm{N}=30)$.

\begin{tabular}{|c|c|c|c|}
\hline Demographic Data & Frequency (\%) & $\begin{array}{l}\text { Association with } \\
\text { Knowledge Score } \\
(p-\text { Value })^{*}\end{array}$ & $\begin{array}{l}\text { Association with Practice } \\
\text { Score } \\
\text { (p-Value) }\end{array}$ \\
\hline $\begin{array}{l}\text { Age (in years) } \\
20-25 \\
26-30\end{array}$ & $\begin{array}{l}14(47 \%) \\
16(53 \%)\end{array}$ & 0.32 & 0.21 \\
\hline $\begin{array}{l}\text { Gender } \\
\text { Male } \\
\text { Female }\end{array}$ & $\begin{array}{l}10(33 \%) \\
20(67 \%)\end{array}$ & 0.30 & 0.41 \\
\hline $\begin{array}{l}\text { Educational Qualification } \\
\text { General Nurse Midwifery } \\
\text { Bachelor of Science } \\
\text { Post Bachelor of Science }\end{array}$ & $\begin{array}{l}23(77 \%) \\
6(20 \%) \\
1(3 \%)\end{array}$ & 0.5 & 0.45 \\
\hline $\begin{array}{l}\text { Work experience of Oncology Unit } \\
\text { Below } 1 \text { year } \\
1-5 \text { year }\end{array}$ & $\begin{array}{l}10(33 \%) \\
20(67 \%)\end{array}$ & 0.23 & 0.34 \\
\hline $\begin{array}{l}\text { Attended any certification course(s) } \\
\text { in Oncology Nursing? } \\
\text { Yes } \\
\text { No }\end{array}$ & $\begin{array}{l}6(20 \%) \\
24(80 \%)\end{array}$ & $0.00^{*}$ & 0.38 \\
\hline
\end{tabular}

*fisher's exact test; df (29) $=2.05$ at 0.05 level of significance

Table 2: Frequency, percentage distribution, mean, standard deviation and ' $\mathrm{t}$ ' Value of pre-test and post-test knowledge and practice score of the participants $(\mathrm{N}=30)$.

\begin{tabular}{|c|c|c|c|c|c|c|}
\hline \multicolumn{7}{|c|}{ Knowledge } \\
\hline \multirow{2}{*}{$\begin{array}{l}\text { Assessment } \\
\text { Score }\end{array}$} & \multirow{2}{*}{ Grading } & \multicolumn{2}{|l|}{ Pre-test } & \multicolumn{2}{|l|}{ Post-test } & \multirow{2}{*}{ 't' Value } \\
\hline & & $f(\%)$ & Mean \pm SD & f (\%) & Mean \pm SD & \\
\hline $0-10$ & Poor & $00(0 \%)$ & \multirow{3}{*}{$17.5 \pm 2.28$} & $00(0 \%)$ & \multirow{3}{*}{$27.03 \pm 1.73$} & \multirow{3}{*}{26.78} \\
\hline $11-20$ & Average & $30(100 \%)$ & & $00(0 \%)$ & & \\
\hline $21-30$ & Good & $00(0 \%)$ & & $30(100 \%)$ & & \\
\hline \multicolumn{7}{|c|}{ Practice } \\
\hline $0-4$ & Very Poor & $00(0 \%)$ & \multirow{4}{*}{$9.13 \pm 1.52$} & $00(0 \%)$ & \multirow{4}{*}{$13.8 \pm 1.09$} & \multirow{4}{*}{28.91} \\
\hline $5-8$ & Poor & $11(37 \%)$ & & $00(0 \%)$ & & \\
\hline $9-12$ & Average & $19(63 \%)$ & & $04(13 \%)$ & & \\
\hline $13-16$ & Very Good & $00(0 \%)$ & & $26(87 \%)$ & & \\
\hline
\end{tabular}

*df $(29)=2.05$ at 0.05 level of significance 
scored between 11-20 (Average) in Pre-test. However, in the post-test, the majority $(100 \%)$ of participants scored between 21-30 (Good). Thereby, indicating an improvement in Knowledge score after implementation of a structured teaching program on safe handling of chemotherapeutic drugs. Data also depicts that mean ( \pm SD) pre-test and post-test knowledge score was 17.5 $( \pm 2.28)$ and $27.03( \pm 1.73)$ respectively. The calculated ' $\mathrm{t}$ ' value was 26.78 that indicates a significant difference between mean pre and post-test knowledge scores.

Table 2 shows that the Maximum (63\%) participants scored between 09-12 (Average) in Pre-test. However, in the post-test, the majority $(87 \%)$ participants scored between 13-16 (Good). Thereby, indicating an improvement in practice score after implementation of a structured teaching program on safe handling of chemotherapeutic drugs. Data also depicts that mean ( \pm SD) pre-test and post-test practice score was 9.13 ( \pm 1.52 ) and $13.8( \pm 1.09)$ respectively. The calculated ' $t$ ' value was 28.91 that indicates a significant difference between mean pre and post-test practice scores.

\section{Discussion}

Chemotherapeutic drug handling is the most critical part in oncology care units and nurses play a vital role when we talk about it. Nurses should be proficient in handling chemotherapeutic drugs safely. The present study was conducted to assess the effectiveness of structured teaching Program on knowledge and practice regarding safe handling of chemotherapeutic drugs among nurses working in oncology care unit at selected tertiary care hospital, Noida. The findings of the present study are discussed according to the study objectives and results. Chemotherapeutic drug Preparation, administration, and disposal pose the highest risks for accidental exposure to hazardous drugs [12]. Therefore, nurses who are working in oncology care unit need to be educated regarding safe handling of chemotherapeutic drugs. Moreover, it has been observed that nurses who have in-depth knowledge on drug handling were very confident than those with average understanding [13]. Hosen MS, et al. also reported similar findings [14].

Present study findings revealed improvement in knowledge after administration of structured teaching program regarding safe handling of chemotherapeutic drugs. Similarly, study conducted by Angel RG, et al. showed mean knowledge score of Pre-test 6.78 ( \pm 1.24) and post-test $19.11( \pm 1.23)$ and the ' $t$ ' value of 44.63 which is significant at 0.001 level of significance [15]. Another study conducted by Hosen MS, et al. also reported that nurses do not have adequate knowledge about use of personal safety equipment's and regarding safe handling of chemotherapeutic drugs [14]. Furthermore, the current study discerns that the level of knowledge regarding safe handling of chemotherapeutic drugs among nurses was significantly associated with certification program in the field of oncology nursing. The results were supported by Bolbol, et al. stating that the knowledge level of nurses about cytotoxic drugs was not satisfactory pre intervention due to lack of training courses related to cytotoxic drugs handling [16]. This can be corroborated from the fact that certification program uplifts the knowledge base and upgrade nursing personnel with the latest guidelines and technology in the same field they are working which ultimately yield better results in the form of quality care [17]. Improvement in knowledge is then expected to bestow good practices which subsequently increase patient satisfaction. However, present study finding was contradicted with Elshamy, et al. [18] and Chaudhary, et al. [19] who reported that fewer nurses mentioned that there are nursing care guidelines for procedures for dealing with patients receiving Chemotherapeutic drugs as well as presence of in-service training programs.

Findings of study conducted by Arul $\mathrm{P}$ revealed similar findings. Majority (90.62\%) of nurses were moderately skilled and after structured teaching program and post-test shows significant improvement in skills and cent percent was highly skilled [20]. Another study conducted by Mahdy NE, et al. also reported highly statistically significant differences between mean scores of the pre- and post-guidelines intervention of nurses' knowledge, practices and attitude regarding safe handling of cytotoxic drugs [21]. Therefore, it sums up the fact that nurses dealing with chemotherapeutic drugs on daily basis should be streamlined on regular basis in the form of workshops, on job trainings, in-service educations, continuing education etc. in order to prevent them from occupational hazards and safeguard life of others in the vicinity.

\section{Limitations}

The study was limited to a single set-up, without a control group and small sample size that limits the generalization of present study findings.

\section{Recommendations}

In Future comparative study can be conducted using educational methods i.e. lecture or hands-on-based training in improving knowledge and skill of nurses regarding safe handling of chemotherapeutic drugs. Also, post-test of knowledge and practice score can be conducted at regular intervals to rule out the retention of knowledge and skill.

\section{Conclusion}

The results of this study concluded that implementation of the structured teaching program regarding safe-handling of chemotherapeutic drugs had positive effect on improving nurses' knowledge and practice related to Receiving, Transporting, Preparation and Administration of cytotoxic drugs, Use of PPE and Handling cytotoxic waste. 


\section{Conflict of Interest}

None.

\section{Funding}

None.

\section{References}

1. Bray F, Ferlay J, Soerjomataram I, Siegel RL, Torre LA, et al. (2018) Global Cancer Statistics 2018: GLOBOCAN estimates of incidence and mortality worldwide for 36 cancers in 185 countries. CA Cancer J Clin 68: 394-424.

2. Forouzanfar $\mathrm{MH}$, Afshin A, Alexander LT, Anderson HR, Bhutta ZA, et al. (2016) Global, regional, and national comparative risk assessment of 79 behavioural, environmental and occupational, and metabolic risks or clusters of risks, 1990-2015: A systematic analysis for the Global Burden of Disease Study 2015. Lancet 388: 1659-1724.

3. Plummer M, de Martel C, Vignat J, Ferlay J, Bray F, et al (2016) Global burden of cancers attributable to infections in 2012: A Synthetic analysis. Lancet Glob Health 4: e609-e616.

4. (2018) World Health Organization. Cancer.

5. Rombaldi F, Cassini C, Salvador M, Saffi J, Erdtmann B (2009) Occupational risk assessment of genotoxicity and oxidative stress in workers handling anti-neoplastic drugs during a working week. Mutagenesis 24: 143-148.

6. Fawcett N (2019) National Comprehensive Cancer Network. Chemotherapy drugs can harm cancer care workers.

7. Live Science Staff (2011) Nurses Exposed to Toxic Cancer Drugs, Study Finds. My health news daily.

8. Fernandes NM, Pelissari IG, Cogo LA, Santos Filha VA (2016) Workplace Activity in Health Professionals Exposed to Chemotherapy Drugs: An Otoneurologic Perspective. Int Arch Otorhinolaryngol 20: 331-338.

9. Ratner P, Spinelli JJ, Beking K, Lorenzi M, Teschke K, et al (2010) Cancer incidence and adverse pregnancy outcome in registered nurses potentially exposed to antineoplastic drugs. BMC Nurs 9: 01-11.

10. Kaur R (2017) Knowledge about Safety Measures regarding Handling of Chemotherapeutic Agents among Staff Nurses in a Tertiary Care Teaching Hospital. Curr Trends Diagn Treat 1: 76-79.
11. Devi S, Sharma P, Kaur S, Banipal R (2019) Knowledge and attitude regarding safe handling of chemotherapeutic drugs among nurses- a cross-sectional. International Journal of Current Research 11: 6380-6386.

12. US Department of Health \& Human Services; Centers for Disease Control and Prevention; National Institute for Occupational Safety and Health (2004) Preventing occupational exposures to antineoplastic and other hazardous drugs in health care settings.

13. Veritya R, Wisemana T, Reama E, Teasdaleb E, Richardsona A (2008) Exploring the work of nurses who administer chemotherapy. European Journal of Oncology Nursing 12: 244-252.

14. Hosen MS, Hasan M, Islam MS, Raseduzzaman MM, Islam MT, et al. (2019) Evaluation of knowledge and practice of handling chemotherapy agents by nurses: A multi-center studies in Bangladesh. Int J Community Med Public Health 6: 4175-4180.

15. Angel R G, Soli TK (2017) Effectiveness of structured education on safe handling and disposal of chemotherapeutic drugs among nursing students. Int $\mathrm{J}$ Pharmacology Clin Res 1: 15-18.

16. Bolbol SA, Hassan AA, Naggar-El SA, Zaitoun MF (2016) Role of occupational health and safety program in improving knowledge and practice among nurses exposed to chemotherapy at zagazig university hospitals, Egyptian Journal of Occupational Medicine 40: 219-235.

17. Coleman EA, Coon SK, Lockhart K, Kennedy RL, Montgomery R, et al. (2010) Outcomes. The Journal of Nursing Administration 40: S35-S42.

18. K Elshamy, M El-Hadidi, M El-Roby, M Fouda (2010) Health hazards among oncology nurses exposed to CDs drugs. Afr J Haematol Oncol 1: 70-78.

19. Chaudhary R, Karn BK (2012) Chemotherapy-knowledge and handling practice of nurses working in a medical university of Nepal. Journal of Cancer Therapy 3: 110-114.

20. Arul PA (2016) Study to Assess the Effectiveness of Structured Teaching Program For Nurses Administering Intravenous Chemotherapy, In PSG Hospital, Coimbatore. Tamil Nadu: Dr. M G R Medical University.

21. MahdyNE, Rahman AA, Hassan HA (2017) Cytotoxic Drugs Safety Guidelines: Its Effect on Awareness and Safe Handling Practices of Oncology Nurses. IOSR Journal of Nursing and Health Science 6: 22-33. 